\title{
MIDAS
}

Museus e estudos interdisciplinares

$4 \mid 2014$

Varia e dossier temático: "Museus, utopia e urbanidade"

\section{Epopeia Paulista: A experiência do ateliê-residência no Museu de Arte Contemporânea da Universidade de São Paulo}

Epopeia Paulista: The experience of a studio-residence in the Museum of Contemporary Art of the University of São Paulo

\section{Alecsandra Matias de Oliveira}

\section{OpenEdition}

\section{Journals}

\section{Edição electrónica}

URL: http://journals.openedition.org/midas/654

DOI: $10.4000 /$ midas.654

ISSN: 2182-9543

\section{Editora:}

Alice Semedo, Paulo Simões Rodrigues, Pedro Casaleiro, Raquel Henriques da Silva, Ana Carvalho

\section{Refêrencia eletrónica}

Alecsandra Matias de Oliveira, « Epopeia Paulista: A experiência do ateliê-residência no Museu de Arte Contemporânea da Universidade de São Paulo », MIDAS [Online], 4 | 2014, posto online no dia 10

fevereiro 2015, consultado no dia 10 dezembro 2020. URL : http://journals.openedition.org/midas/654 ; DOI : https://doi.org/10.4000/midas.654

Este documento foi criado de forma automática no dia 10 dezembro 2020.

\section{c) (i) (2)}

Midas is licensed under a Creative Commons Attribution-NonCommercial-ShareAlike 3.0 International License 


\title{
Epopeia Paulista: A experiência do ateliê-residência no Museu de Arte Contemporânea da Universidade de São Paulo
}

\author{
Epopeia Paulista: The experience of a studio-residence in the Museum of \\ Contemporary Art of the University of São Paulo
}

\section{Alecsandra Matias de Oliveira}

\section{NOTA DO EDITOR}

Artigo recebido a 04.03.2014

Aprovado para publicação a 17.10.2014

1 No dia 26 de dezembro de 2004, foi inaugurado, num dos lugares mais antigos e tradicionais de São Paulo, a Estação da Luz, o painel Epopeia Paulista, de Maria Bonomi, resultado de um extenso trabalho de criação e execução. A obra ocupa a galeria da maior interligação metropolitano-comboio da América do Sul, ligando as linhas A, B, D, E e F da Companhia Paulista de Trens Metropolitanos com as linhas 1, 3 e 4 do metropolitano. Diariamente, o painel, dedicado aos imigrantes e migrantes, é visto por cerca de um milhão de pessoas, renovando a sua narrativa sobre a cidade de São Paulo - metrópole de múltiplos povos.

Quatro anos antes, Maria Bonomi respondia ao convite da Companhia Paulista de Trens Metropolitanos para criar uma obra de arte na Estação da Luz. No estaleiro da obra, Meire Selli (arquiteta da Companhia Paulista de Trens Metropolitanos), Maria Bonomi e Rodrigo Velasco (arquiteto e colaborador da artista), encontram-se para discutir os detalhes da construção de uma arte pública no local. Sob a Rua Mauá, entre as escavações, um muro, a 
ser demolido, é o primeiro dado do projeto. Construído a partir de tijolos, em três camadas escalonadas, serve para contenção de terra para a passagem dos trilhos, 15 metros abaixo do arruamento. A ideia de permanecer com os escalonamentos na obra artística surge como recurso para «guardar a memória do muro e dos homens (...) que [o] construíram» (Sousa e Okita 2005, 30). Acrescente-se o facto de que, para Bonomi, os relevos permitem o "escalar" do visitante.

3 A primeira versão do projeto do painel Epopeia Paulista procura uma racionalidade: a proposta apresenta um painel moldado na própria parede do túnel, incorporado à obra de engenharia. $O$ processo de construção utilizaria mão de obra operária, concreto e moldes da própria construtora, agregando valor estético a uma solução utilitária. A experiência de outros painéis elaborados por Bonomi mostra a possibilidade de uso de materiais e de mão de obra vinda da construção civil, tal como o painel Igreja Cristo Salvador (Cruz Torta), os painéis Paisagem e Memória (no Maksoud Plaza Hotel) e Construção de São Paulo (na estação de metropolitano Jardim São Paulo). Note-se que talvez tenha sido essa característica de unir a produção artística e a construção civil uma das motivações que levou a Companhia Paulista de Trens Metropolitanos a convidar a artista para a realização do painel da Estação da Luz. Porém, num segundo momento, confrontando os cronogramas e os planos de trabalho das construtoras envolvidas na reforma da Estação da Luz, mostrou que o painel deveria ser produzido num outro local e não no estaleiro das obras, como se pensara originalmente. A peça precisaria de ser dividida em placas e, depois de pronta, transposta para os subterrâneos da Luz. Qual seria o local mais adequado? $\mathrm{O}$ ateliê da artista comportaria as dimensões já percecionadas no projeto? Estas constituem as preocupações prementes daquela iniciativa.

Vencer as dimensões do muro (73 $\mathrm{m} \times 3 \mathrm{~m}$ ) consistiu no primeiro desafio. Bonomi optou por uma leitura visual a partir do centro em "V". ${ }^{1} \mathrm{O}$ conceito original de três camadas escalonadas permaneceu e essas camadas seriam coloridas e legíveis pelo tato - o aspeto táctil da obra constitui-se como algo muito importante na visualidade. Para Maria Bonomi, esse foi o conceito básico desde o projeto inicial. 0 tema foi selecionado pela Companhia Paulista de Trens Metropolitanos que propôs retratar a história do centenário da Estação da Luz na ótica dos migrantes, sobretudo os nordestinos, nunca lembrados. Seria uma homenagem a esses homens que roçam o campo ou pastam as cabras. A artista aderiu integralmente à proposta. Para contar a história dos migrantes, Bonomi recorreu à literatura de cordel ${ }^{2}$. As homenagens são estendidas aos imigrantes - milhares de espanhóis, portugueses, italianos e outros que chegam à cidade pela Estação da Luz, a partir dos séculos XIX e XX. Ao aliar-se à temática e às personagens envolvidas na conceção do painel, a Epopeia Paulista tornou-se marca da presença multiétnica existente na cidade.

5 Em Epopeia Paulista, os tipos humanos da cidade de São Paulo são o enfoque principal. Essa dimensão humana delineia-se, a partir dos objetos e das marcas dessa gente que chega à cidade nos 100 anos de existência da Estação da Luz. Quando Maria Bonomi decide utilizar os objetos perdidos ou deixados na estação (roupas, ferramentas, óculos, instrumentos musicais, brinquedos, entre outros) tem em mente o desejo de «cravar esses objetos deixados na secção de achados e perdidos, coisas encontradas nas escavações para a reforma da Estação da Luz» (Sousa e Okita 2005, 32). Soma-se aos objetos a própria condição da artista - também uma imigrante. Essa arqueologia urbana completa-se com a adoção da literatura de cordel. O resultado configura-se na mescla de etnias que 
representa a cidade de São Paulo. Os traços identitários da metrópole encontram-se estampados em cada uma das figuras.

6 Ao escolher a linguagem da literatura de cordel, Maria Bonomi assume uma função social e cognitiva na retoma da memória popular através da arte contemporânea. No painel, localizado no metropolitano de São Paulo, o reencontro com as imagens do cordel ${ }^{3}$, sufocadas pelo entorno urbano, adquire conteúdo político ao procurar a justiça social, quer para a população instalada na cidade, quer para os atuais migrantes. O painel deixa explícita a intenção de indagação social. Não há uma intenção de resgate de uma forma de cultura perdida, mas a demonstração das diferenças que a cidade apresenta - essas diferenças não são parte do passado, constituindo uma presença real.

O processo de execução da obra é também uma ação coletiva. Este é construído em contexto de ateliê (pela artista e pelos colaboradores mais próximos); no museu (por artistas profissionais, por artistas espontâneos e por voluntários); num barracão industrial (com engenharia e mão de obra operária) e, por fim, no local de destino (o restauro com apoio dos colaboradores mais próximos). No exercício de execução da obra, a memória também está presente e materializa-se em novos objetos, tais como as formas e os moldes que constituem o painel. A artista compartilha as suas experiências com muitas pessoas e juntas concebem cada parte da obra, transformando o trabalho ético e criador - último reduto do transformar a matéria em cultura.

8 Maria Bonomi, disposta a interagir com o público, revela os caminhos da produção artística, a convite da direção do Museu de Arte Contemporânea da Universidade de São Paulo (daqui em diante apenas Museu de Arte Contemporânea), ocupando o espaço expositivo anexo do museu, na Cidade Universitária, de 15 de abril a 30 de maio de $2004{ }^{4}$ O espaço transforma-se em oficina e integra as comemorações dos 70 anos da Universidade de São Paulo e os 450 anos da cidade de São Paulo, retomando o conceito de artista-residente. Isto reforça o papel do museu, não somente como órgão difusor, mas também como produtor de arte contemporânea.

9 A experiência da artista em ateliês instalados em museus não é, totalmente, nova. Retoma-se no ano de 1971, quando a artista experimenta um exercício semelhante no Museu de Arte Moderna do Rio de Janeiro, onde o público acompanha o processo de criação e de realização de sua xilogravura ou ainda o projeto Espaço Vivo, executado por Nicolas Vlavianos e idealizado por Bonomi, no qual o público também assiste de perto à criação da obra de arte. Contudo, nestes episódios, o público não interage com a equipa da artista, observando apenas o processo. A ação no Museu de Arte Contemporânea, nesse sentido, é radical. o público é o produtor do painel - parceiros anónimos e desconhecidos da artista.

10 O relacionamento de Maria Bonomi com o Museu de Arte Contemporânea é bastante sólido. A artista participou em diversas ações e exposições organizadas pela instituição desde 1963. Existem 19 obras de Maria Bonomi no acervo, entre elas a gravura Como se Fossem Palavras (1975). A partir de 2003, a artista estreitou esse relacionamento de um modo especial. O projeto expositivo Nave dos Insensatos traz para o convívio do museu artistas brasileiros, tais como Claudio Tozzi, Ivald Granato, Antonio Henrique Amaral, Arcangelo Ianelli, José Roberto Aguilar, Maria Bonomi, entre tantos outros. Nesse mesmo ano, as comemorações dos 40 anos do Museu de Arte Contemporânea levam a artista a doar a obra Rosácea (1998), como presente pelo aniversário do museu. O somatório desses episódios serve como contexto e impulso ao convite para a instalação do ateliê-residência. 
11 O ateliê-residência, instalado no Museu de Arte Contemporânea, recebe contribuições de diversas pessoas: uma «obra de mil mãos» (Leão 2004, 7), como a artista gosta de denominar o painel. Na oficina do Museu de Arte Contemporânea, o público pode vivenciar a obra de quatro formas:

- secção de trabalho livre: observação do processo de realização do painel, através de agendamento prévio;

- operário-artista: o Museu de Arte Contemporânea seleciona jovens xilogravadores, estudantes da Universidade, que se tornam colaboradores da equipa de Maria Bonomi nas atividades de gravação de matrizes;

- interlocutores: todos os dias, a artista ou sua equipa conversam com um pequeno grupo de pessoas interessados na obra;

- público especial: como o painel proposto por Maria Bonomi para a Estação da Luz proporciona uma "leitura táctil" das gravações em alto e baixo relevo, a oficina do Museu de Arte Contemporânea atende o público portador de deficiências visuais.

12 Na oficina do Museu de Arte Contemporânea, as matrizes são desenhadas e escavadas. São cerca de 980 matrizes, entre objetos e gravuras de cordel: 185 placas são gravadas a partir de mais de 700 desenhos de objetos e imagens de cordel. Durante a oficina aberta, ocorre, paralelamente, no saguão de entrada do Museu de Arte Contemporânea - Anexo, uma exposição de objetos, fotografias, gravuras e textos explicativos, para além da apresentação do processo de produção da obra, desde os primeiros esboços até a moldagem das placas em concreto. Essa ação, posteriormente, desdobra-se, em 2004 e 2005, na exposição Olhar Impertinente que percorre os espaços do Museu de Arte Contemporânea no Parque Ibirapuera e no Campus de São Carlos, numa ação conjunta com a Escola de Engenharia de São Carlos (Universidade de São Paulo).

Os objetos da secção de Achados e Perdidos da Estação da Luz tornam-se a metáfora perfeita para representar esses povos. Assinala-se que os objetos perdidos ou esquecidos são o conceito básico da questão da memória em Epopeia Paulista. Os objetos transformamse no modo de recuperação das memórias individuais e, ao mesmo tempo, configuram-se no meio de identificação que liga construtores e fruidores do painel. Dos objetos mais comuns (quem nunca esqueceu ou perdeu um guarda-chuva?) aos mais inusitados (como cadeiras de rodas ou véus de noiva - como foram perdidos!?), a artista e sua equipa amealharam as histórias que envolvem a Estação da Luz. Depoimentos de pessoas que perderam algo na estação são utilizados por Maria Bonomi como matéria para a criação artística. Esse conjunto que mescla pessoas, narrativas e objetos compõe a memória "coisificada" e "ressignificada" impregnada na obra.

Outra orientação que surge dos objetos reside na presença da metáfora da "mão", em face da interação desta com o ato de trabalhar. A "mão" que fabrica os objetos e as mãos que os abandonam ou esquecem. Tem-se como fator contribuinte para o reforço dessa metáfora o número elevado de ferramentas e de instrumentos de trabalho perdidos e recuperados pelo painel. No entalhe dos objetos, as mãos também atuam de modo decisivo: rasgam os sulcos e gravam na madeira a imagem inversa que será transposta para o concreto. A mão está na representação, na confeção e no toque (na sensibilização) da obra - uma vez que entre suas funções básicas estão o ver e o sentir através do toque.

15 A leitura estética da obra deve ter em consideração ainda a divisão do painel em três cores: amarelo ocre, vermelho-terra e branco puríssimo. A existência de cores é uma exigência da Companhia Paulista de Trens Metropolitanos. No trabalho de Bonomi, 
especialmente, nas gravuras, as cores são aplicadas comummente - traço herdado de Seong Moy $^{5}$. Porém, a aplicação de cores ao concreto consiste num desafio, somente transposto no final de 2003, quando chega, ao Brasil, a produção de cimento branco estrutural. A partir de então, é possível fixar o padrão vermelho, branco e amarelo. As cores representam o elemento constitutivo do painel que ordena sua leitura. Compõe três ciclos da economia paulista (café, indústria e serviços) em três camadas de concreto sobrepostas, cada uma delas com padrões e desenhos distintos.

A parte da peça amarela ocre faz alusão às terras nordestinas - às terras secas e abandonadas. A acumulação dos elementos, nessa faixa regista a presença da população nordestina na cidade de São Paulo, através da literatura de cordel, uma forma artesanal de gravura - a mais tradicional do país e de alguns países da América Latina. A ideia centra-se em ir buscar reproduções de histórias e personalidades tradicionais, como Padre Cícero, Lampião, ou factos contemporâneos, como os atentados às Torres Gémeas, em Nova Iorque (Estados Unidos). Cordelistas famosos, como Patativa do Assaré, são relembrados no painel. Para essa tarefa, Maria Bonomi conta com uma equipa de entalhadores especializados nessa linguagem popular.

No vermelho-terra está a "terra roxa" sulina fértil. A vermelho estão representados cerca de 700 objetos esquecidos na Estação, que são esculpidos em madeira e, posteriormente, "gravados" no concreto. Na faixa vermelha, a acumulação dos elementos, em especial, narra as "memórias perdidas" de uma série de viajantes que esquece ou abandona objetos: roupas, ferramentas, óculos, instrumentos musicais, brinquedos, entre outros. Assinala-se que durante o processo de execução da obra, outros objetos de estimação do público participante são incorporados, contribuindo para essa arqueologia da cidade de São Paulo. Note-se que essa arqueologia é quase "doméstica": são objetos que, na sua maioria, pertencem ao quotidiano e que, por essa razão, estabelecem profunda identidade com indivíduos comuns.

Já o branco é ilustrado com figuras abstratas - linha de expressão mais reconhecida da artista. A faixa branca abre espaço para a acumulação dos elementos geométricos e cortes no espaço-tempo. A parede em branco traz inscrições e, sobretudo, as linhas retas representam os trilhos do metropolitano ou da estrada de ferro. Por vezes, os elementos dessa faixa interferem nas demais faixas, indicando o entrelaçamento entre os tempos e culturas no quotidiano urbano. $O$ vértice do painel é branco. Para Maria Bonomi, o branco significa «uma nova realidade». É a visão do passageiro quando chega à Estação - o futuro a ser construído na cidade (Histórias de Chegadas e Partidas 2004, s/p.).

o painel - macro gravura - segue a orientação do espaço para o qual é concebido (um corredor inteiro da estação com $73 \mathrm{~m}$ de cumprimento e $3 \mathrm{~m}$ de altura). A escolha desse local faz com que a artista pense em algo que ofereça a visualização de uma história, como se fosse possível assistir a um filme. «É uma vitrine da memória paulista», reitera Bonomi (Histórias de Chegadas e Partidas 2004, s/p). ${ }^{6}$ A comparação com o cinema é razoável. Tal como uma fita, composta por milhares de quadros, a criação do painel é o resultado da união das placas, dispostas uma ao lado da outra. Talvez o apelo cinematográfico também seja uma das motivações para o desvio do modelo característico de Maria Bonomi que reside no abstracionismo e na inserção dos fotogramas criados pela linguagem da literatura de cordel. A artista utiliza a figuração para evocar os ciclos de crescimento da cidade e as vivências das personagens que constroem a metrópole. Em Epopeia Paulista a figuração conta uma história que, a cada novo olhar, pode ser recriada. 
20 Nesse ponto, percebem-se as relações entre arte, história e memória. Bonomi transforma o painel em veículo transmissor de conhecimento e reflexão. o fluxo migratório que constitui a cidade de São Paulo, particularmente no século XX, é evocado como facto histórico significativo. Contudo, a artista faz uso das diversas memórias pessoais que aludem ao facto histórico para recriá-lo a cada novo momento. A interface entre a história e a memória constrói e ordena a leitura estética da obra. As memórias individuais presentes em cada objeto perdido ou esquecido reconstituem a história de São Paulo e vice-versa. Tudo isso ocorre por intermédio da obra de arte que utiliza a literatura de cordel e a metáfora dos objetos para evocar outras memórias que auxiliam nessa reconstituição. Nesse sentido, a arte transforma-se em meio de conhecimento, em instrumento de reflexão.

21 Epopeia Paulista demonstra como a cidade de São Paulo e a sua região metropolitana têm origem em fluxos migratórios, com destaque para o êxodo rural (especificamente, quando se recorda o grande número de ferramentas agrícolas abandonadas ou esquecidas). A mudança de ambiente, do campo para a cidade, cria uma erosão de identidades sociais, uma desestabilização de personalidade, efeitos surgidos da fragmentação de comunidades e da quebra do laço com a natureza. O painel resgata essa sensação de rutura e, simultaneamente, convoca para a reflexão da "unidade na diferença" - o que une os imigrantes é seu percurso na cidade de São Paulo, representado no painel, como a passagem pela Estação da Luz (porta de entrada na cidade - início de uma vida de trabalho).

Em maio de 2004, durante a oficina no Museu de Arte Contemporânea, Bonomi introduz a escrita no painel como recurso expressivo. Uma escrita significante, embora não legível, transformando-se numa textura que lembra cartas e documentos. Artistas e visitantes são estimulados a redigir - com ferramentas elétricas - pequenos textos, numa escrita automática, que mescla filosofia, astrofísica, matemática, história, poesia e qualquer coisa. Os textos estão presentes no painel, em impressão negativa, em diversos idiomas, tais como: inglês, português, espanhol e japonês. A leitura desses textos é possível somente com o uso de espelho. Reforça-se que a escrita marca presença em outras produções de Bonomi, como por exemplo, Como se Fossem Palavras (1975), Páginas (1997) e Essência: Sete Horizontes (1998) - em cada uma das obras desempenha papel diferenciado. Em Epopeia Paulista transforma-se em mensagem a ser descodificada pelas próximas gerações. A profusão de temas que é abordada pelos escritos dá conta da diversidade que rege a dinâmica da obra.

As dimensões finais do painel impedem a preparação de todas as formas no espaço do Museu de Arte Contemporânea. Decide-se fazer a montagem por etapas, com base num esquema na escala 1:50. Nesse esquema estão representadas e numeradas 185 placas, 90 da cor vermelha, 54 brancas e 41 amarelas que compõe o painel. A montagem assemelhase à edição de uma longa-metragem, na qual somente se pode imaginar a continuidade. Mais uma vez o painel remete para os recursos cinematográficos. Nessa oportunidade, reproduz a montagem e a edição de uma longa-metragem. Maria Bonomi e sua equipa só conhecem integralmente o painel no momento da instalação na Estação da Luz. 0 sequenciamento dos moldes inicia-se a partir do posicionamento das placas de MDF, cortadas em formato geométrico, cujas linhas abstratas dão forma e condicionam os lugares e os objetos. Sobre essa base, a artista seleciona cada matriz e objeto - a composição é aleatória - leques, bules, chapéus e cornetas racionalizam o espaço da obra. 

se em formas de MDF, uma síntese de fibras de madeira, agregada por pressão e colagem, que não pode ser exposta à humidade. Isso é um problema técnico a ser resolvido pela equipa de Maria Bonomi, porque o cimento, que agrega os materiais do concreto, exige água em grande quantidade. Na fábrica da empresa Reago (em Jundiaí), monta-se uma pista de produção para a concretagem do painel. Depois do preenchimento de cada forma é preciso um trabalho de vibração do material para que possam dissipar-se as bolhas formadas. Prefere-se a vibração manual que, aliada ao uso das formas de MDF, causa uma desmoldagem problemática - partes do concreto ficam nas formas e há comprometimento na leitura do painel. Simultaneamente à fixação das 185 placas de concreto ocorre o restauro do painel - as cicatrizes, as bolhas e as falhas são recuperadas por especialistas e artistas.

Para Maria Bonomi «a ação do painel, ou seja, todo o seu processo de execução é mais importante do que ele mesmo» (Sousa e Okita 2005, 38). A artista satisfaz-se com a criação coletiva, especialmente, porque vê Epopeia Paulista como uma obra de arte urbana e pública. 0 espaço do museu onde a obra é confecionada deixa de ser contemplativo para ser interativo. A questão reside na partilha da imaginação da artista com o coletivo, através de intervenções simultâneas no objetivo artístico. A obra é resultado da fruição espacial coletiva em algo que difere de uma participação coletiva ou da interatividade comum. Esse diferencial advém da postura que a artista adota em relação ao painel. Os riscos são totais. A criação entrega-se ao devaneio da construção de um lugar de memórias partilhadas.

trabalho no museu é, particularmente, instigante ao tema da memória. Durante 45 dias, o espaço museológico, dotado de uma pequena marcenaria, com serras, lixadeiras e um pequeno "barracão" para a guarda das ferramentas, serve de suporte para a confeção da obra em processo. Essa atividade é intitulada Maria Bonomi, Artista Residente. Como se observa o ateliê é, inicialmente, aberto aos alunos de artes da Universidade de São Paulo, grupos de escolas públicas e artistas voluntários interessados em trabalhar na produção das matrizes, contudo, a iniciativa recebe a adesão do público em geral. 0 espaço museológico - como o espaço da memória - vê-se perante a ação transformadora da arte. Não está em jogo a contemplação estética, mas a ação criadora do objeto estético.

Para o Museu de Arte Contemporânea, a receção do ateliê representa a personificação de um dos desafios mais comuns dos museus contemporâneos: superar a sua função de templo, de depósito de "tesouros intocáveis", deixando de ser o criador/reiterador de mitos e estereótipos para se transformar num lugar de produção de arte e de conhecimento. Em geral, os museus tentam explicitar como os objetos se transformam em cultura, aguçar a consciência crítica sobre a memória e criar condições para que o público exerça interações com os objetos (Costa 2004, 75). As ações de ver, de ensinar, de fazer e de refletir convergem para a criação do painel. Maria Bonomi ressalta o papel do museu como espaço sagrado, voltado para o conhecimento que, acrescido à atividade do ateliê, potencializa o exercício de reflexão sobre o fazer artístico (Epopeia Paulista: Do MAC à Estação da Luz 2004).

O Museu de Arte Contemporânea tem incentivado a produção de arte pública e a recuperação da experiência processada pelas intervenções artísticas (fotografia, vídeo, literatura específica, jogos interativos, palestras, oficinas, entre outras atividades), para além de possuir no seu contexto um espaço reservado, denominado jardim de esculturas, estimulando, também, a exibição de obras de arte em parques, jardins e praças. Na 
reflexão adotada pelo museu, a arte pública situa-se na interface entre o espaço institucionalizado e o espaço urbano. Inclui-se, nesse ponto, a reflexão sobre a cidade e as suas configurações na esfera da memória coletiva, lembrando que grande parte dessa memória coletiva ainda é dominada pelas instituições, especialmente as museológicas. $\mathrm{Na}$ ação do ateliê de Maria Bonomi, o museu serve como espaço da ação criadora, subvertendo a noção de museu como espaço "sagrado" e imutável - algo que altera radicalmente as funções museológicas instituídas que, tradicionalmente, tentam conservar a memória coletiva como algo imutável.

Nesse sentido, retoma-se a conceção artística contemporânea que ensina: a obra de arte é trespassada por diferentes mediações que devem ser explicitadas pelo museu - no caso do ateliê, a obra está em processo e os participantes estão em constante interação. Ao deixar em evidência os critérios e as estratégias da criação do painel, o museu estabelece um contraponto com a indústria de entretenimento que se estende ao campo da cultura, demonstrando o seu diferencial (Costa 2004, 75). O museu como "lugar da memória" transforma-se em guardião e produtor da narrativa (passado, presente e futuro) em Epopeia Paulista. Não é somente o representante da tradição inalterada, da ludicidade, do entretenimento, do lugar da "comercialização de memórias", mas o espaço da reflexão e da partilha destas.

Esse exercício apresenta os seus conflitos e negociações. A convivência entre artistas, voluntários, público, alunos e funcionários da Universidade de São Paulo e, particularmente do museu, nem sempre se mostra harmoniosa. A greve de 2004 na universidade causa impacto nos trabalhos da Oficina. Maria Bonomi negoceia com os grevistas: faz uma paralisação de 15 minutos. Os motivos da não adesão são entendidos pelos funcionários, uma vez que a execução do painel não implica uma relação direta com o funcionamento da universidade.

31 Outro detalhe perturbador: a baixa adesão dos alunos, especialmente dos dedicados às artes plásticas na universidade. $\mathrm{O}$ anúncio nos veículos de comunicação da universidade parece não ter motivado a participação da comunidade universitária. A apatia é vencida e, gradualmente, alunos de outros cursos aderem ao ateliê em diferentes trabalhos paralelos, tais como o filme produzido pela pós-graduanda Vera Cristina Athayde, da Escola de Comunicações e Artes da Universidade de São Paulo $^{7}$, e a produção do documentário realizado pela universidade. Na verdade, os maiores entusiastas da obra pertencem a um ambiente externo à Universidade de São Paulo. A execução do trabalho estimula "pessoas comuns" - admiradores da arte, mas sem envolvimento ou experiência com o fazer artístico.

Destaca-se, ainda, o projeto de arte-educação que acompanha os trabalhos da oficina Museu de Arte Contemporânea. Educadores, artistas e voluntários unem-se para transmitir o processo criativo do painel Epopeia Paulista a deficientes visuais, mentais, surdos e portadores de outras necessidades especiais. A própria conceção da obra já traz consigo o conceito tátil da obra como primordial. 0 relevo das placas gravadas nas pontas dos dedos alimenta a linha do projeto "arqueológico" de descoberta das memórias de São Paulo, organizado por Maria Bonomi.

o painel permite diversas experiências, mas, sobretudo, estimula a inclusão de um público que, em geral, está excluído da fruição da obra de arte - a essas pessoas oferece-se o acesso às memórias da cidade e também à memória da execução do painel, uma vez que muitos talham a madeira em experiência singular. Essa movimentação no ambiente 
museológico é algo especial: uma experiência única que inaugura uma nova interação entre o fazer artístico, a memória e a fruição desses elementos.

Acrescente-se que o contexto propiciado pelas efemérides de 2004 contribui para a confluência dos trabalhos na Oficina Museu de Arte Contemporânea. Os desdobramentos ligados ao painel Epopeia Paulista surgem a partir de 2004. Na data emblemática dos 450 anos da cidade de São Paulo, Maria Bonomi e outros artistas estão completamente envolvidos pelas comemorações - as lembranças da fundação da cidade, da Semana de Arte Moderna de 1922 e, particularmente o IV Centenário de São Paulo, presidido por Francisco Matarazzo Sobrinho, são temas de exposições, séries de televisão, peças teatrais e uma série de movimentações artístico-culturais que tentam resgatar fragmentos da história da cidade.

A relação do público com o painel Epopeia Paulista inicia-se antes mesmo da inauguração. Começa no espaço museológico, onde pessoas permitem que as suas histórias sejam incorporadas no painel, na ânsia de sair do anonimato. Como se vê, um grupo privilegiado participa na conceção da obra, no Museu de Arte Contemporânea. Outro grupo, ainda, acompanha a obra até à sua instalação. Cerca de mil pessoas registam a sua escrita no painel em sete idiomas. Contem-se, também, as inúmeras pessoas que interagem com os desdobramentos do painel (exposições, instalações, subprodutos, filmes). 0 painel multiplica-se em infinitas possibilidades e cada uma delas atinge um público renovado. No corredor da estação da Luz, as pessoas esforçam-se por descobrir o que representa cada uma das imagens. Identificar-se com esse conjunto é um exercício quotidiano dos utentes. Assim como no momento da sua produção no espaço museológico do Museu de Arte Contemporânea, o painel propõe uma leitura cinematográfica em plena Estação da Luz, em movimento pelos passageiros que passam apressados pelo local. Mas, além dessa fruição fotográfica, o grande painel pode ser "lido com as mãos sensíveis" dos deficientes visuais que utilizam o sistema de transporte. Em ambos os casos, os recortes, as texturas e os objetos, incrustados no concreto, propiciam flashes sobre a história e a cultura "dos povos" de São Paulo. 


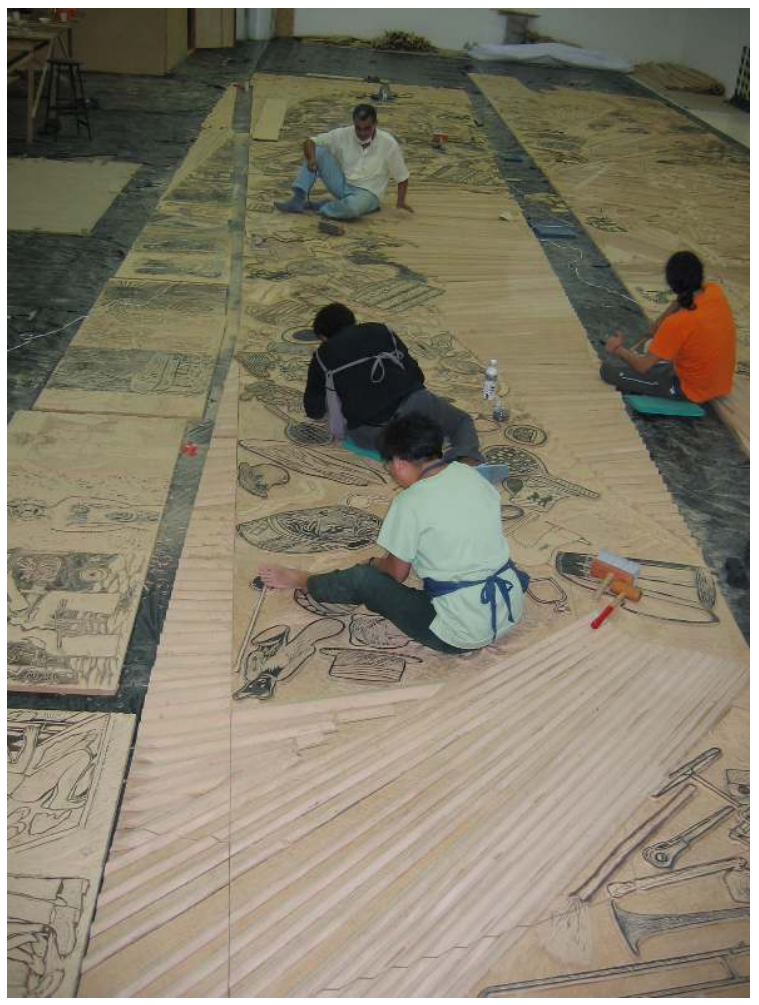

Fig. 1 - Mostra Ateliê Maria Bonomi (trabalho na oficina Museu de Arte Contemporânea). De 15 de abril a 30 de maio de 2004, Anexo do Museu de Arte Contemporânea, Universidade de São Paulo (c) Percival Tirapeli

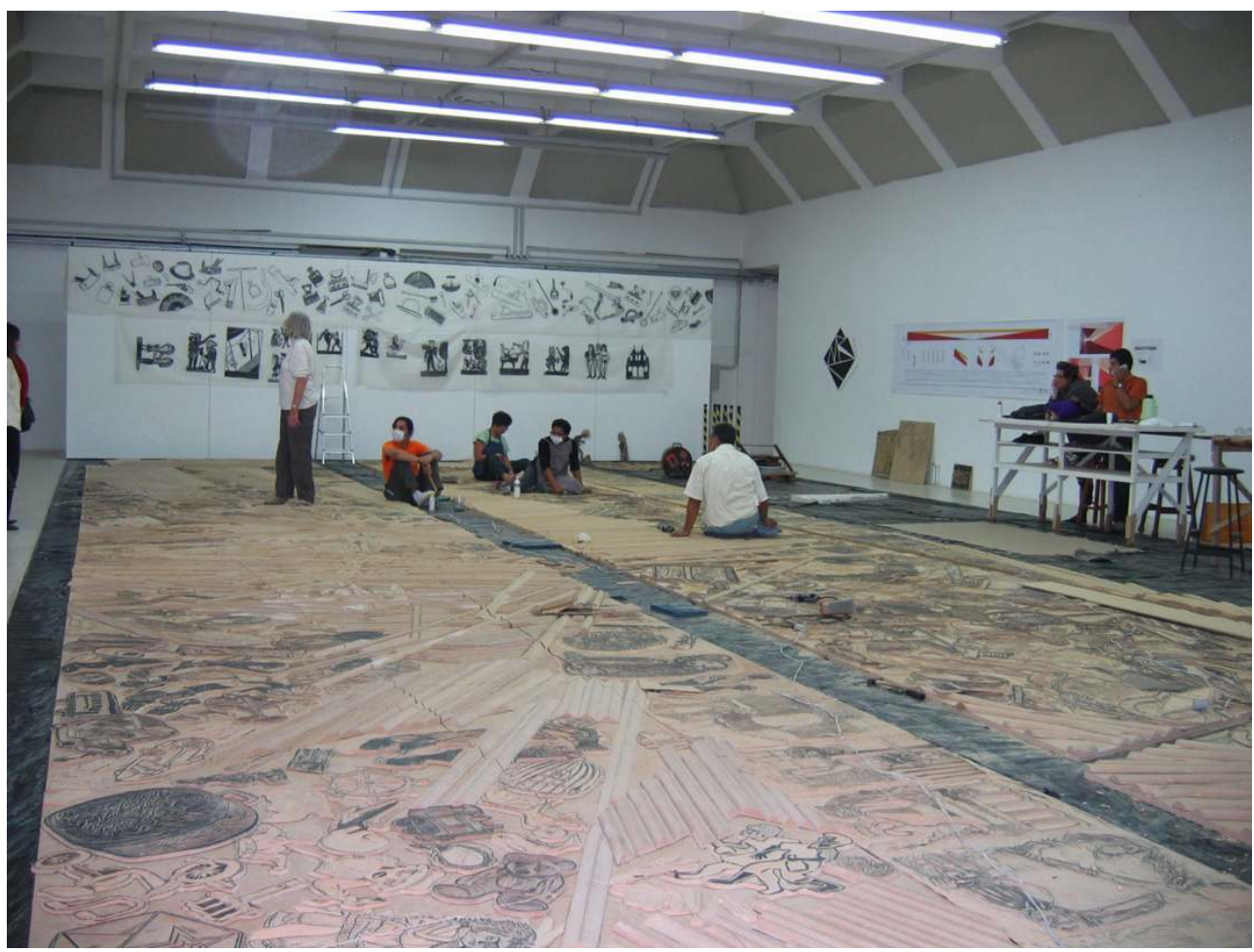

Fig. 2 - Mostra Ateliê Maria Bonomi (Trabalho na Oficina Museu de Arte Contemporânea). De 15 de abril a 30 de maio de 2004. Anexo do Museu de Arte Contemporânea, Universidade de São Paulo (c) Percival Tirapeli 


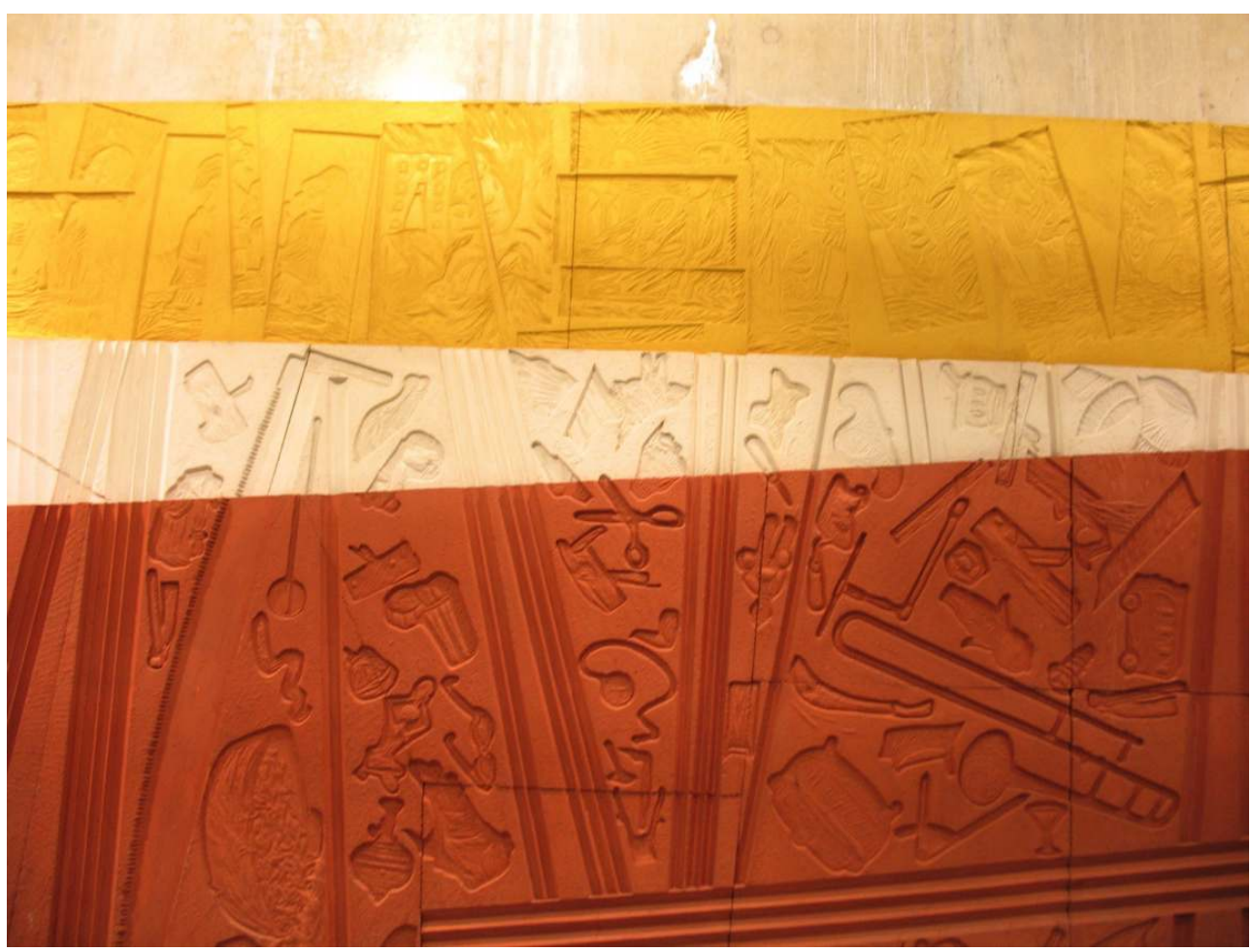

Fig. 3 - Maria Bonomi, Epopeia Paulista (detalhe), 2004. Mural em concreto pigmentado, $7300 \times 300$ cm. Estação da Luz, São Paulo, Brasil

(c) Percival Tirapeli

Os passageiros de Epopeia Paulista mal se dão conta que a leitura da obra pressupõe o levantamento dos aspetos estéticos e educacionais que envolvem a criação e execução da obra. Epopeia Paulista e a Estação da Luz organizam-se e intervêm entre si, formando um conjunto dinâmico que não cessa de acontecer e de se modificar na medida da aglomeração de pessoas, da incidência da luz do dia ou da noite, da posição dos passageiros, do ir e vir dos comboios. Como o painel narrativo de uma identidade coletiva, aplicada diretamente na parede estrutural, Epopeia Paulista leva em conta a frequência da Estação da Luz. Hoje, grande parte da população que transita no corredor reside em regiões periféricas de São Paulo. Ao lembrar Giulio Carlo Argan, Maria Bonomi lembra que, numericamente, a maioria da população habita os subúrbios periféricos e são esses habitantes os protagonistas mais diretos da chamada função urbanos (Argan 1995, 32). Nessas regiões longínquas, à margem da cidade, é onde se inicia um trabalho de recuperação visual e social, com a participação de todos e, de fora para dentro, conduzir à renovação da emoção no quotidiano.

A materialidade da obra de Maria Bonomi provoca a apreciação estética involuntária dos utentes daquela estação pela dimensão da obra e pela temática. Sendo o painel instalado no corredor de ligação entre duas vias de transporte, nada mais é do que uma sinalização de passagem, uma vez que não se visualiza a obra integralmente, a não ser que se passe por toda a sua extensão. Em território de passagem, indica a permanência imanente do passageiro. Contudo, esse olhar fragmentado e quotidiano pode ser seletivo, mas tende a não ser reflexivo pela urgência da passagem, ou seja, o transeunte está sempre em ritmo acelerado. A monumentalidade do painel procura reverter esse quadro: estimula o olhar apreciativo, crítico e criador - em alguma passagem pelo painel, o fruidor verá algo que prenderá sua atenção - tal como um "esgrimista visual". A estética de Maria Bonomi 
consciente das suas inspirações conflui erudito e popular; identidade e coletividade; biografia da artista e histórias individuais; memórias da cidade de São Paulo e reflexão política. Numa lógica visual, o painel traz referências à territorialidade, identidade, história e memória - está circundado pela alta densidade cultural da região Luz.

Em síntese, a retrospetiva sobre a poética e sobre o processo de criação e execução do painel mostra a atualidade e coerência estética e política da artista-autora, a sua fecundidade e relevância. Epopeia Paulista é uma homenagem à população anónima e à metrópole paulista, já tão globalizada. Uma homenagem feita por artistas e voluntários numa oficina que por algum tempo ocupa o espaço museológico, tornando-se um desafio à transcendência do quotidiano das pessoas ditas comuns e também às funcionalidades do museu. É uma prova da potencialidade do indivíduo e do coletivo brasileiro, já que toda a obra se constrói por referenciais sociais e literários, essenciais no panorama cultural nacional e num ambiente de ateliê-residência em museu.

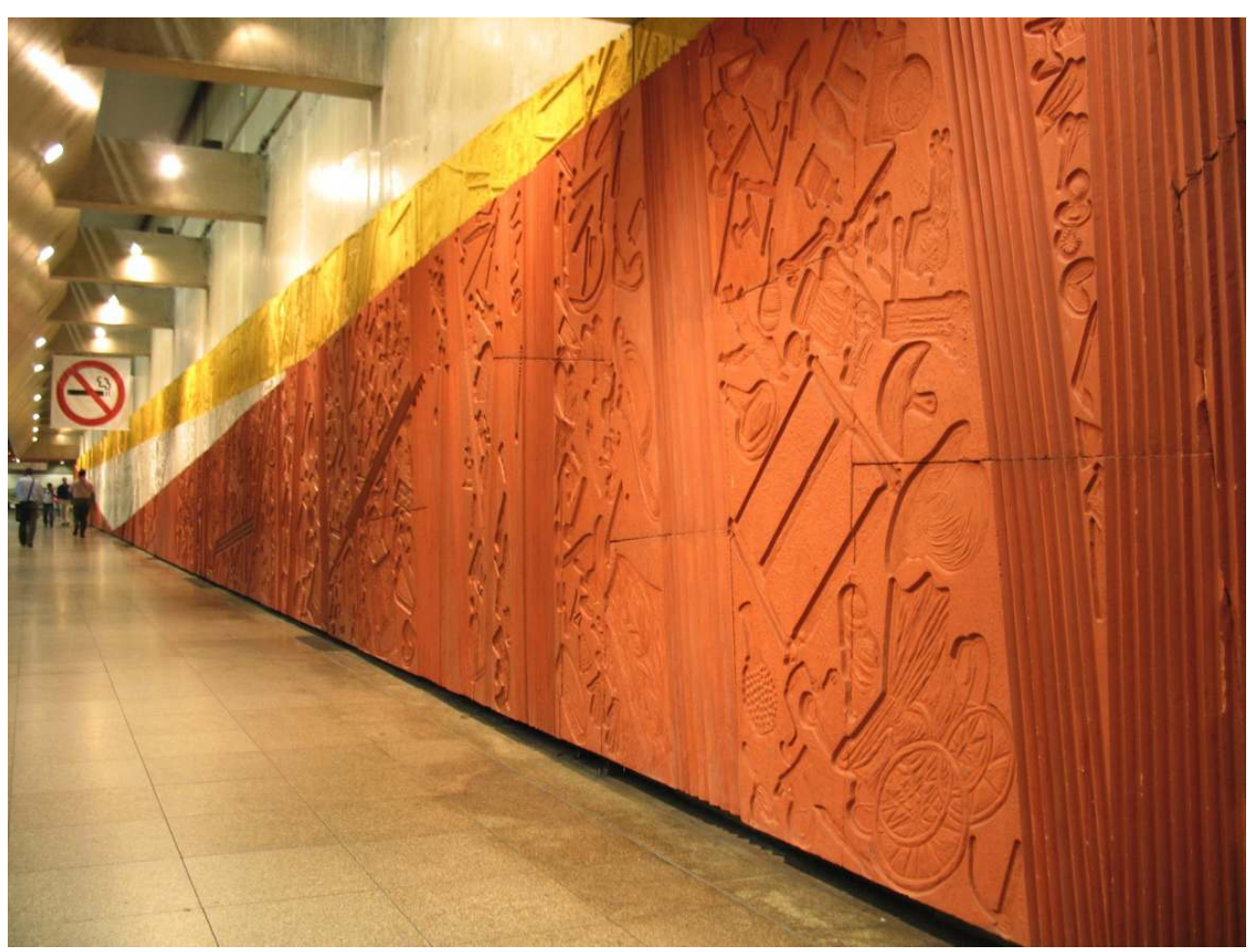

Fig 4 - Maria Bonomi, Epopeia Paulista (detalhe), 2004. Mural em concreto pigmentado, $7300 \times 300$ cm. Estação da Luz, São Paulo, Brasil

(c) Percival Tirapeli

\section{BIBLIOGRAFIA}

Ajzenberg, Elza, org. 2006. Arte Contemporânea e Suas Interfaces. São Paulo: Programa de PósGraduação Interunidades em Estética e História da Arte da Universidade de São Paulo e Museu de Arte Contemporânea. 
Argan, Giulio Carlo. 1995. História da Arte como História da Cidade. São Paulo: Martins Fontes.

Costa, Helouise. 2004. "Práticas Museológicas em Museus de Arte." In Arteconhecimento, organizado por Elza Ajzenberg, 73-78. São Paulo: Museu Arte Contemporânea da Universidade de São Paulo.

Epopeia Paulista: Do MAC à Estação da Luz. 2004. Documentário produzido pela TV Universidade de São Paulo.

Histórias de Chegadas e Partidas. 2006. INVESTNEWS. s/p.

Leão, Isabel. 2004. “Uma Obra a Mil mãos.” Jornal da Universidade de São Paulo. (de 29 de janeiro a 4 de fevereiro de 2004), ano XXII, 798: 32-35.

Luyten, Joseph Maria. 2007. O Que é Literatura de Cordel. São Paulo: Editora Brasiliense.

Oliveira, Alecsandra. 2008. “A Poética da Memória: Maria Bonomi e Epopeia Paulista.” Tese de doutoramento, Escola de Comunicações e Artes da Universidade de São Paulo.

Sousa, Marcos de, e Hiro Okita. 2005. Epopeia Paulista na Estação da Luz. São Paulo: Mandarim Editora.

\section{NOTAS}

1. A solução consiste em abrir o painel do centro às bordas, como se fosse uma abertura do olhar do viajante ao desembarcar em uma "nova vida". A convergência ganha expressividade quando recai sobre a cor branca do painel, reforçando a alusão ao devir - aos migrantes e imigrantes, São Paulo seria "um futuro em branco" (a construir) (Epopeia Paulista: Do MAC à Estação da Luz 2004).

2. Literatura de cordel é um tipo de poema popular que une texto e imagens. Geralmente, é impresso em folhetos expostos para venda pendurados em cordas ou cordéis. Tem origem no nordeste do território brasileiro, em especial nos estados de Pernambuco, da Paraíba, do Rio Grande do Norte e do Ceará. Alguns dos muitos cordelistas famosos são: Apolônio Alves dos Santos, Patativa do Assaré, Firmino Teixeira do Amaral, João Ferreira de Lima, João Martins de Athayde, Leandro Gomes de Barros e Manoel Monteiro (Luyten 2007, 13).

3. Xilogravuras talhadas, quase sempre, na madeira da cajazeira, matéria-prima mole - fácil de ser trabalhada e abundante no nordeste do Brasil. Entre os gravadores populares mais conhecidos, destacam-se: Manoel Serafim, Inocêncio da Costa Nick, o Mestre Noza, Zé Caboclo, Enéias Tavares Santos, J. Borges, entre outros.

4. Em janeiro de 2004, a professora Elza Ajzenberg, à época diretora do Museu de Arte Contemporânea da Universidade de São Paulo, convida a equipa de Maria Bonomi a ocupar o Anexo do museu, na Cidade Universitária, para a montagem das matrizes.

5. Pintor e artista gráfico, Seong Moy nasceu em Cantão, na China, em 1921. Em 1931 está nos Estados Unidos, onde estuda pintura. Como gravador, recebe uma bolsa para o Stanley William Hayter Atelier, em 1948, e é premiado em 1955 pelas suas ilustrações em xilogravura a partir dos poemas de Li Po (chinês, século VIII). As suas gravuras têm sido amplamente expostas e reproduzidas em revistas. Moy ensinou em muitas faculdades e universidades, para além de ter dirigido a Escola Seong Moy de Pintura e Artes Gráficas em Princetown, Massachusetts, até ao seu falecimento em 2013.

6. Vitrine que, segundo a artista, lembra um pouco a proposta de A Rosa Púrpura do Cairo, filme de Woody Allen que transita entre a fantasia e a realidade (Histórias de Chegadas e Partidas 2004, s/p).

7. Durante a greve, surge o filme Poética de um Processo: Maria Bonomi, de Vera Cristina Athayde com depoimentos de migrantes e imigrantes, artistas e voluntários sobre a experiência no ateliê transitório. 


\section{RESUMOS}

O presente estudo tem como objetivo relatar a experiência de um ateliê-residência desenvolvido pela artista Maria Bonomi no espaço expositivo do Museu de Arte Contemporânea da Universidade de São Paulo (Brasil) em abril de 2004. A pesquisa envolve conceitos relativos à museologia, à história e à história da arte e tem como questão central a prática artística contemporânea proposta num espaço museológico de forma interativa. $\mathrm{O}$ ateliê contou com a participação de artistas e de voluntários, suscitando discussões sobre o modo de criação e de execução da obra de arte pública. Nesta reflexão, toma-se como exemplo o painel Epopeia Paulista que hoje se encontra no corredor de ligação entre o metropolitano e a Companhia Paulista de Trens Metropolitanos (na Estação da Luz, São Paulo). Além do interesse para a arte contemporânea, o painel tornou-se uma obra-referência na criação e no processo de narrativas de memórias de diversas etnias presentes na cidade de São Paulo.

This study aims to report the experience of an artist-in-residence developed by artist Maria Bonomi, in April 2004, in the exhibition space of the Museum of Contemporary Art, University of São Paulo (Brazil). The research involves concepts related to museology, history and art history and has its central issue in the contemporary artistic practice proposed in an interactive museum space. The workshop, with the participation of artists and volunteers, raised discussions on how to create and implement a public work of art. The case study for this deliberation is the Epopeia Paulista panel which can be found in the corridor connecting the subway and the Paulista Company of Metropolitan Trains (at the Luz Station - São Paulo). In addition to the mode of production of contemporary art, the panel becomes a work-reference in the creation and the process of memories narratives of various ethnicities present in the city of São Paulo.

\section{ÍNDICE}

Palavras-chave: arte, memória, história, Maria Bonomi, Museu Arte Contemporânea Universidade de São Paulo

Keywords: art, memory, history, Maria Bonomi, Contemporary Art Museum S. Paulo University

\section{AUTOR}

\section{ALECSANDRA MATIAS DE OLIVEIRA}

Licenciada em História pela Faculdade de Filosofia, Letras e Ciências Humanas (1995), mestre em Ciências da Comunicação pela Universidade de São Paulo (2003) e é doutora em Artes Visuais pela mesma universidade (2008). Atualmente é especialista em Cooperação e Extensão Universitária na Universidade de São Paulo (Brasil). Tem experiência na área das Artes e desenvolve investigação sobre os seguintes temas: Arte, Arte Contemporânea, Arte Brasileira, História, História da Arte e Crítica de Arte. É autora do livro Schenberg: Crítica e Criação (Edusp - Editora da Universidade de S. Paulo, 2011). alemaoli@usp.br 